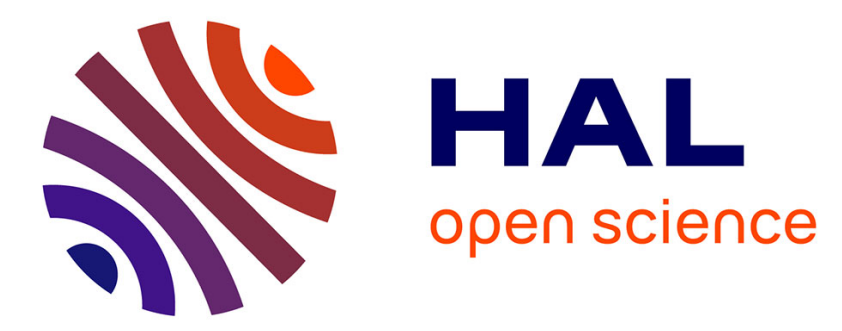

\title{
Linking peel and tack performances of pressure sensitive adhesives
}

Vivek Pandey, Antoine Fleury, Richard Villey, Costantino Creton, Matteo

Ciccotti

\section{> To cite this version:}

Vivek Pandey, Antoine Fleury, Richard Villey, Costantino Creton, Matteo Ciccotti. Linking peel and tack performances of pressure sensitive adhesives. Soft Matter, 2020, 16 (13), pp.3267-3275. $10.1039 / \mathrm{c} 9 \mathrm{sm} 02172 \mathrm{~h}$. hal-02555347

\section{HAL Id: hal-02555347 https://hal.science/hal-02555347}

Submitted on 27 Apr 2020

HAL is a multi-disciplinary open access archive for the deposit and dissemination of scientific research documents, whether they are published or not. The documents may come from teaching and research institutions in France or abroad, or from public or private research centers.
L'archive ouverte pluridisciplinaire HAL, est destinée au dépôt et à la diffusion de documents scientifiques de niveau recherche, publiés ou non, émanant des établissements d'enseignement et de recherche français ou étrangers, des laboratoires publics ou privés. 


\title{
Linking peel and tack performances of pressure sensitive adhesives
}

\author{
Vivek Pandey, ${ }^{a}$ Antoine Fleury, ${ }^{a}$ Richard Villey, ${ }^{b}$ Costantino Creton (D) *a and \\ Matteo Ciccotti (D) *a
}

\begin{abstract}
The performances of Pressure Sensitive Adhesives (PSA) are generally evaluated using different loading geometries such as tack, peel and shear tests. It is difficult to link the behaviors of PSAs in these different geometries, and to predict the result of one test from another, because the confinement of a soft and dissipative material prevents the use of standard fracture mechanics, which separates the interface debonding behavior from the dissipation associated with the bulk deformation. We present here an original experimental investigation based on the modeling strategy proposed by Creton and Ciccotti[1]. Using instrumented versions of both peel and tack measurements, we compared the adherence performances of a series of model PSAs based on styrene-isoprene block copolymers, while identifying the mesoscale mechanisms at play during debonding. This analysis method allows us to model the contribution of the large strain rheology of the PSAs in the total work of debonding. We clearly show that both the adherence performances and local mechanisms can be closely related between peel and tack when considering both similar confinement and a similar strain rate of the fibrils that are spontaneously formed during debonding. While the overall adherence properties change by a factor of 3 between the different samples, the peel tests only present a minor $+20 \%$ bias in adherence, which can be attributed to the combination of a $10 \%$ increase in the average stress and a $10 \%$ increase in the maximum strain of the fibrils. This improvement in the understanding of the PSA performances opens the way to a more sound mechanical design of PSA based joints.
\end{abstract}

\section{Introduction}

Pressure Sensitive Adhesives (PSA) are used as a safe and versatile means to precisely assemble, package and label, thanks to their high level of adherence on very different substrates and their very easy implementation. ${ }^{2}$ Yet the debonding of PSAs, which is used to assess performance, is a classic example of the difficult and unsolved issue of fracture in confined soft viscoelastic materials. The performances of PSAs as evaluated with different loading geometries such as tack, peel and shear tests, ${ }^{3}$ which are not easily related to one another since standard fracture mechanics cannot be applied to separate the interface debonding behavior from the energy dissipation related to bulk deformation of the whole joint. ${ }^{1}$ While the shear test is specifically designed to probe the long term performance of the adhesive under a moderate load and is outside the scope of this paper, both the peel and tack tests can be used to assess the adherence of a PSA under the action of a mostly tensile and rapid loading. Because of its ease of implementation, the peel test is the workhorse of the industry. Yet because of the presence of the flexible backing, imposing a rather complex and self-adjusting loading geometry on the adhesive, experimental investigations focusing on the debonding mechanisms acting in the adhesive itself have been mostly carried out with the probe tack test. ${ }^{4-7}$ The transposition of the results of the probe tack test, which is well adapted to the development stage of new adhesives, to a peel test would be desirable, but to the best of our knowledge it has never been done quantitatively. In particular, the presence of a complex debonding region in both the peel and tack tests ${ }^{8,9}$ ( $c f$. Fig. 1) where the adhesive undergoes cavitation and the very large strain of a spontaneously formed fibrillar network (also called stringing) has defied many modeling attempts over the past 70 years. $^{1}$

Starting from the pioneering work of Kaelble, it was recognized that the viscoelastic properties of PSAs are a key ingredient controlling the bonding performance, yet only linear (low strain) properties were considered by most authors. ${ }^{10-13}$ Dahlquist $^{14}$ proposed that the elastic component of the modulus $\mu^{\prime}$ at $1 \mathrm{~Hz}$ needed to be below a certain value to form a good contact with a rough surface and that a relatively high value of the loss factor $(\tan (\delta)$ between 0.3 and 0.5 at $1 \mathrm{~Hz})$ was required to provide 


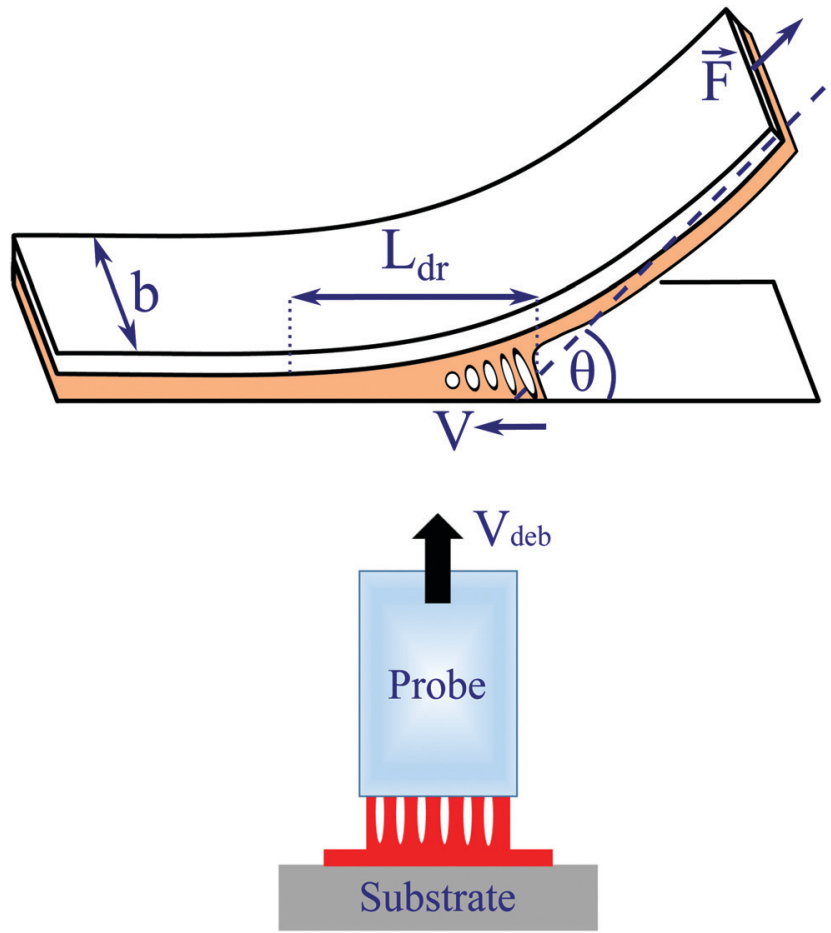

Fig. 1 Fibrillar debonding region in the peel and tack tests.

resistance to debonding. These properties are easily achieved with a sparsely physically or chemically cross-linked polymer network using a polymer with a low glass transition temperature (around $50-70{ }^{\circ} \mathrm{C}$ below the usage temperature) as also discussed by Zosel in a seminal paper. ${ }^{5}$ However, several recent investigations have pointed out the major role played by the non-linear (large strain) viscoelastic properties of these polymers in the adherence performances, in particular during slow debonding, where the fibrillated regions reach the largest extensions. ${ }^{15-17}$ While peel, a steady-state test of debonding, and probe tack, a transient test, have generally been investigated independently, the recent development of novel instrumented peeling techniques and related modeling procedures make it now possible to carry out a quantitative analysis of the debonding region for both cases. Hence, the peel and tack performances can now be compared and are shown here to be related to different expressions of the same kind of local debonding mechanisms.

Among the commercially available families of PSAs one distinguishes three large groups: solvent-borne acrylic adhesives, emulsion acrylic adhesives and block copolymer-based adhesives. ${ }^{18}$ In the present manuscript we focus on a series of blends of styreneisoprene-styrene triblock copolymers, styrene-isoprene diblock copolymers and a hydrogenated tackifying resin that can be easily formulated in a laboratory. While these polymers share very similar rheological properties in the linear domain, they behave very differently under large strain where the polymer architecture is important. ${ }^{19,20}$ We also selected this family of PSAs because their linear, non-linear and adhesive properties have been extensively analyzed in the past. ${ }^{12,19-22}$ This article presents a thorough comparison of the peel and tack performances of this series of adhesives for different loading velocities. Thanks to the insights provided by the instrumented peeling technique, we can compare the peel and tack performances by analyzing the adherence energy, the average stress and the maximum stretch of the adhesives in conditions where the local debonding strain rates of the fibrils are similar.

\section{Sample composition and preparation}

The PSAs used in our experiments are based on styrenic block copolymers (SBC). They are blends of styrene-isoprene-styrene (SIS) triblocks and styrene-isoprene (SI) diblocks synthesized by Dexco (Dow Chemicals and Exxon-Mobil Chemical joint venture). Four different blends were formulated by changing the SI diblock weight percentage (from $0 \%$ to $54 \%$ ) as reported in Table 1. A low molecular-weight and high $T_{\mathrm{g}}$ resin is also added to this blend as a tackifier in order to bring the mixture into the proper rheological window for PSAs. ${ }^{23}$ The tackifying resin must be miscible with polyisoprene, but immiscible with polystyrene. ${ }^{24}$ For this reason, we have used a hydrogenated hydrocarbon resin derived from cyclopentadiene produced by ExxonMobil Chemical, also commercially known as Escorez $5380\left(T_{\mathrm{g}}(\mathrm{DSC}) \sim 40{ }^{\circ} \mathrm{C}\right)$. These tackifiers not only dilute the entanglement network, but also increase the $T_{\mathrm{g}}$ of the blend to give it a tacky behavior. Each of the four different adhesive formulations was prepared using $40 \mathrm{wt} \%$ of the block copolymer blend (SIS/SI as in Table 1) and $60 \mathrm{wt} \%$ of tackifying resin. These compositions are the same as the ones investigated in ref. 19, 20 and 23 , which provided both rheological characterization and tack measurements for comparison.

PSA solutions were prepared by stirring the above formulation with toluene (15 to $25 \mathrm{wt} \%$ polymer) for $24 \mathrm{~h}$ with a magnetic stirrer. The samples for the probe tack experiments were prepared by pouring a quantity of 2.5 to $3 \mathrm{~mL}$ of the solution onto a glass slide $\left(100 \times 25 \times 2 \mathrm{~mm}^{3}\right)$. The samples were first kept under a non-airtight desiccator cover for 24 hours to undergo slow evaporation, and then the solvent was completely evaporated by drying the samples in a vacuum oven at $45{ }^{\circ} \mathrm{C}$ for $24 \mathrm{~h}$. Depending on the polymer concentration and the quantity of poured solution, we could obtain a variable sample thickness in the range of $a_{0}=(150 \pm 25) \mu \mathrm{m}$. The peel samples were prepared according to the same protocol, but using as a substrate a PET backing sheet $\left(160 \times 160 \mathrm{~mm}^{2}\right.$ area, a thickness of $\left.h=52 \pm 2 \mu \mathrm{m}\right)$. After completely drying, the peel samples were cut into strips $\left(160 \times 20 \mathrm{~mm}^{2}\right)$ and protected by a silicon coated liner before use.

Table 1 Sample composition

\begin{tabular}{llllll}
\hline $\begin{array}{l}\text { SIS/SI commercial } \\
\text { name }\end{array}$ & SI, wt\% & $\begin{array}{l}M_{\mathrm{w}}(\mathrm{SIS}), \\
\mathrm{kg} \mathrm{mol}{ }^{-1}\end{array}$ & $\begin{array}{l}\mathrm{wt} \% \mathrm{~S} \\
\text { in SIS }\end{array}$ & $\begin{array}{l}M_{\mathrm{w}}(\mathrm{SI}), \\
\mathrm{kg} \mathrm{mol}^{-1}\end{array}$ & $\begin{array}{l}\mathrm{wt} \% \mathrm{~S} \\
\text { in SI }\end{array}$ \\
\hline VR4100 & 0 & 154 & 15.1 & - & - \\
VR4113 & 19 & 154 & 15.1 & 72 & 15 \\
VR4114 & 42 & 156 & 15.1 & 72 & 15 \\
DPX565 & 54 & 176 & 16.1 & 72 & 16
\end{tabular}




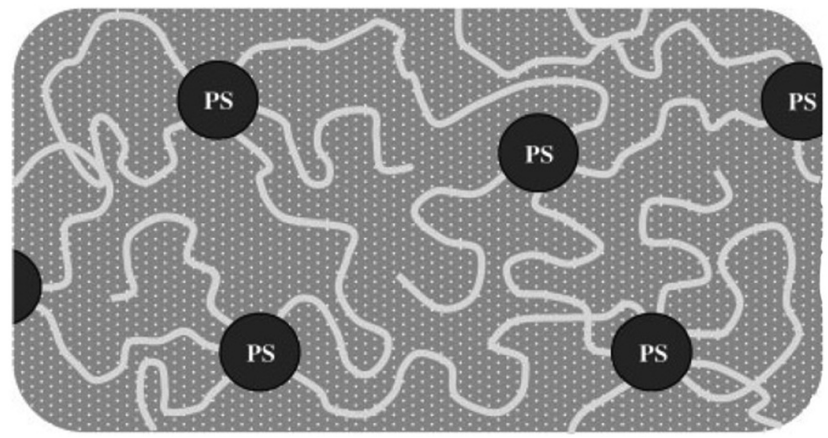

Fig. 2 Schematic of the domain organization of the block copolymer chains and the tackifying resin in the blend. Both triblock copolymers (linking two styrene-rich domains) and diblock copolymers (only linked to one styrene-rich domain) are represented. The tackifying resin remains confined outside of the stryrene-rich domains.

The created PSAs microstructure is thus as follows: the styrene end-blocks of the copolymer chains create glassy domains poor in tackifying resin. Outside of the domains, the long isoprene chains are diluted in the tackifying resin; they are mobile and entangled. Since the volume fraction of the glassy phase is limited to $6 \%$ in the adhesive, the microphase separated structures result in a dilute, but highly regular, density of nanoscale nodules acting as cross-link points ${ }^{20,24}$ as presented schematically in Fig. 2. For pure triblock copolymers, these result in a soft elastic behavior at ambient temperature with an order-disorder transition of about $T_{\text {ODT }} \sim 150-180{ }^{\circ} \mathrm{C}$ where the physical network (resulting from phase segregation) disappears and the polymer can flow as a thermoplastic. ${ }^{25}$ In the final composition of the adhesive, the tackifier has the effect of both diluting the entanglements, therefore softening the material, ${ }^{26}$ and of increasing the glass transition temperature, and hence the dissipation at a fixed temperature. ${ }^{20}$ On the other hand, the diblock copolymer modifies the large strain behavior by reducing the number of bridges between polystyrene domains. ${ }^{19,20,24}$ Yet in the composition regime explored in this study the large strain behavior remains quite elastic in character, with important strain hardening at ambient temperature. ${ }^{19}$

\section{Instrumented peeling test}

The peeling measurements were performed using the instrumented peel test setup developed in our laboratory and previously presented by Villey et $a .^{16}$ ( $c f$. Fig. 3). The adhesive tape is peeled from a flat bar by an Instron testing machine (model 3343), which records the peeling force $F$ while imposing a constant pull-out velocity $V \in[3: 3000] \mu \mathrm{m} \mathrm{s}^{-1}$. The bar, which can be tilted at an angle $\theta \in\left[30^{\circ}: 150^{\circ}\right]$ with respect to the pulling axis of the testing machine, is mounted on a translation stage: it is translated at the same velocity $V$ as the pull-out velocity, resulting in steady peeling at constant angle $\theta$.

In the present measurements, the translating bar is set in a horizontal position in order to obtain peeling at $\theta=90^{\circ}$ as in standard peeling tests [ $c f$. ISO 8510-1 (1990)]. The adhesives are initially bonded on a flat glass substrate that is fixed on the

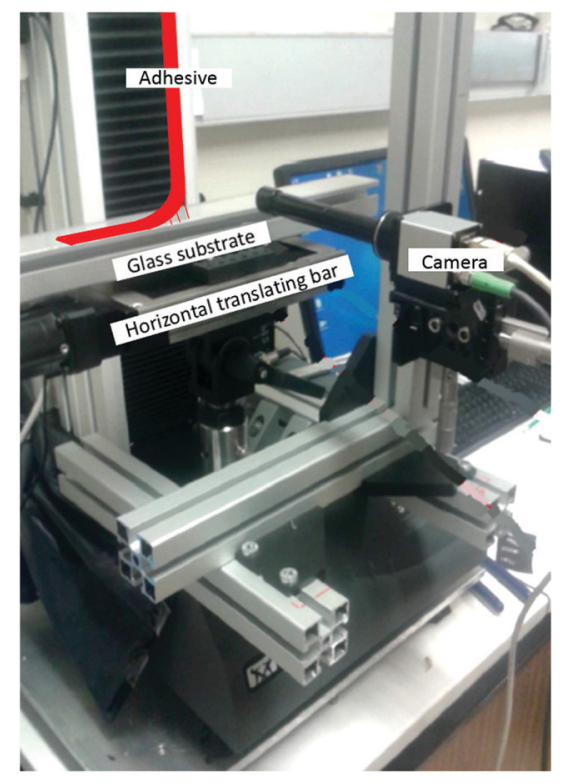

Fig. 3 Peeling test setup. The adhesive tape (sketched in red for clarity) is bonded on a glass substrate on the horizontally translating bar and peeled at a $90^{\circ}$ angle by the testing machine.

translating bar in order to present the same substrate as in the tack measurements. The contact is formed by hand pressure. The peel velocities used here were $V^{\text {peel }}=10,100$ and $1000 \mu \mathrm{m} \mathrm{s}^{-1}$, where steady-state adhesive debonding is observed, with no residues left on the substrate. The measured force reaches a constant value $F^{\text {peel }}$ after going through an initial peak that is neglected in the present measurements. Since the backing is stiff and the peel angle is not too close to $0^{\circ}$, the elastic energy stored in the backing can be neglected and the adherence energy can therefore be obtained by the measured peel force $F^{\text {peel }}$ using the simplified Kendall equation: ${ }^{27} \Gamma^{\text {peel }}=F^{\text {peel }} / b$, where $b$ is the width of the tape.

The application of the instrumented peeling technique described in Villey et al. ${ }^{16}$ allows one to extract valuable details on the debonding mechanisms during steady-state peeling. The shape of the tape backing profile close to the debonding region (where the adhesive is deformed before debonding) is monitored during the peeling experiments using a $1624 \times 1228$ pixel CCD camera equipped with a microscope objective and a frame rate of $10 \mathrm{fps}$ (a resolution between 0.55 and $2.2 \mathrm{px} \mu \mathrm{m}^{-1}$ ). For each frame of the movies (such as the one presented in Fig. 4), the outer profile of the tape backing is extracted using a binarization algorithm that detects the interface between the dark background and the illuminated tape. The tape backing profile does not significantly change with time during steady peeling. We can thus average this profile over 200 frames, which removes detection imperfections and eventually results in a significant increase of the signal-to-noise ratio.

The second step is to fit this average profile with a mechanical model describing the backing as an inextensible elastica that interacts with the substrate through a cohesive zone representing the mechanical behavior of the stretched fibrils in the debonding region as sketched in Fig. 5. Since the fibrils do not appear to slide on the substrate, their direction is obtained by linking a 


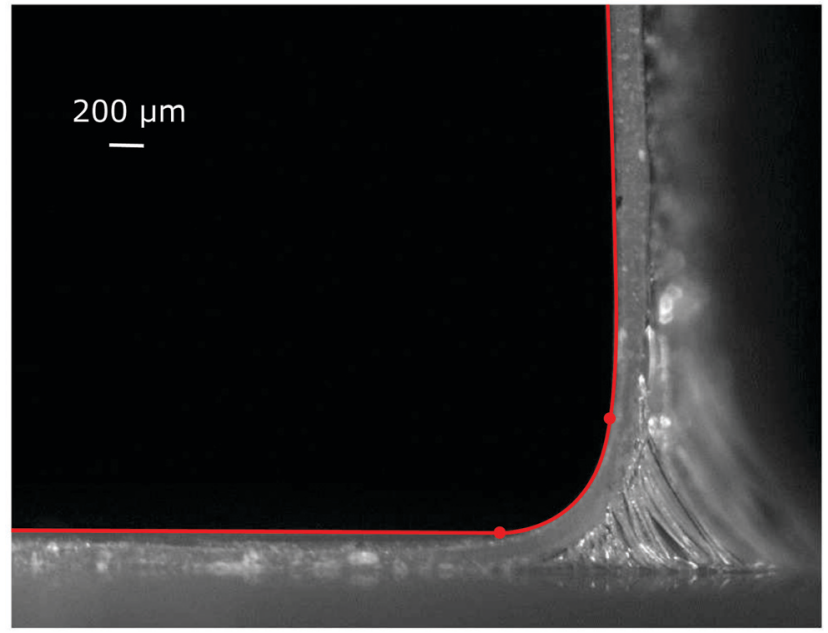

Fig. 4 Typical image of the debonding region in peeling. The red profile is the best fit of the tape backing by the model presented in Fig. 5, with the two red circles as fitting parameters (beginning and end of the cohesive zone).

couple of points that have the same curvilinear distance $s$ along the backing and the substrate. The direction of the stress vector at each point of the backing is assumed to be parallel to the local fibril direction. The stress distribution $\sigma(s)$ applied to the tape

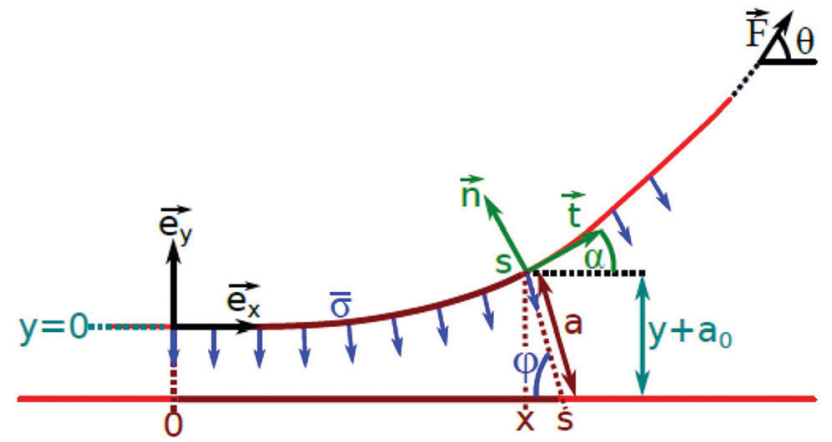

Fig. 5 Modelling of the debonding region in a peeling test as coupling between an elastic flexible backing and a cohesive zone where the fibrils apply a constant stress $\sigma^{\text {peel }}$ parallel to their direction (blue arrows). The length $a$ of the fibril changes from the initial thickness $a_{0}$ to the maximum value $a_{\mathrm{f}}$ at debonding. backing in the debonding region is approximated as an uniform effective stress $\sigma^{\text {peel }}$, which corresponds to a constant tractionseparation curve up to the maximum elongation $a_{\mathrm{f}}-a_{0}$ at debonding ( $a_{0}$ being the thickness of the undeformed adhesive and $a_{\mathrm{f}}$ the length of the longest fibril), where it drops to zero.

All the details about the theoretical derivations and fitting procedure are thoroughly described in Villey et al. ${ }^{16}$ and will only be shortly recalled here. In the standard fitting procedure, the free part of the profile out of the debonding region is first fitted using a stress free elastica model in order to obtain the bending stiffness EI of the backing of each sample. This first step was not possible in the present measurements since the debonding region is very large due to the strong adhesion on the high energy surfaces of the glass substrate. The measurement of EI was thus performed by first peeling the same kind of samples on a lower energy substrate, such as the backing of $3 \mathrm{M} 600$ tape that is coated with a release layer as in Villey et $a .^{16}$ The values obtained are consistent with independent measurements on the PET backing, which provide a Young modulus $E=(3.6 \pm 0.3) \mathrm{GPa}$ and a thickness $h=(52 \pm 2) \mu \mathrm{m}$.

The second step of the fitting procedure consists in fitting the whole profile with the complete mechanical model from Villey et al. ${ }^{16}$ in order to extract the positions of the beginning and of the end of the cohesive zone (red dots in Fig. 4). These two independent fitting parameters allow a direct geometrical calculation of the length $L_{\mathrm{dr}}$ of the debonding region and the length $a_{\mathrm{f}}$ of the longest fibril, which in turn are used to calculate the main peeling parameters, i.e.:

1. The maximum nominal fibril strain:

$$
\varepsilon_{\text {peel }}^{\text {rupture }}=\frac{a_{\mathrm{f}}-a_{0}}{a_{0}}
$$

2. The average stress $\sigma^{\text {peel }}$ in the debonding region through the energy balance between the macroscopic work of the peeling force and the stretch of the fibrils in the cohesive zone: ${ }^{16}$

$$
\Gamma^{\text {peel }}=\frac{F^{\text {peel }}}{b}=\sigma^{\text {peel }}\left(a_{\mathrm{f}}-a_{0}\right)=a_{0} \sigma^{\text {peel }} \varepsilon_{\text {peel }}^{\text {rupture }}
$$

3. The average nominal strain rate of the fibrils in the debonding region:

$$
\dot{\varepsilon}^{\text {peel }}=\frac{V^{\text {peel }}}{L_{\mathrm{dr}}} \varepsilon_{\text {peel }}^{\text {rupture }}
$$

\begin{tabular}{|c|c|c|c|c|c|c|c|c|}
\hline SI (\%) & $V^{\text {peel }}\left(\mu \mathrm{m} \mathrm{s}^{-1}\right)$ & $F^{\mathrm{peel}}(\mathrm{N})$ & $L_{\mathrm{dr}}(\mu \mathrm{m})$ & $a_{\mathrm{f}}(\mu \mathrm{m})$ & $\sigma^{\mathrm{peel}}(\mathrm{kPa})$ & $\varepsilon_{\text {peel }}^{\text {rupt }}$ & $\Gamma^{\text {peel }}\left(\mathrm{J} \mathrm{m}^{-2}\right)$ & $\dot{\varepsilon}^{\text {peel }}\left(s^{-1}\right)$ \\
\hline 0 & 100 & 16 & 1.49 & 1.42 & 656 & 8.5 & 799 & 0.49 \\
\hline 0 & 1000 & 21.9 & 1.79 & 1.50 & 820 & 9.0 & 1096 & 5.2 \\
\hline 19 & 100 & 16 & 2.06 & 1.73 & 548 & 10.5 & 801 & 0.52 \\
\hline 19 & 1000 & 22.9 & 1.90 & 1.67 & 746 & 10.1 & 1146 & 5.2 \\
\hline 42 & 10 & 11.2 & 2.39 & 2.01 & 321 & 12.4 & 562 & 0.05 \\
\hline 54 & 10 & 12 & 2.74 & 2.31 & 281 & 14.4 & 599 & 0.05 \\
\hline 54 & 100 & 13.6 & 2.52 & 2.22 & 342 & 13.8 & 679 & 0.54 \\
\hline 54 & 1000 & 19 & 2.49 & 2.16 & 459 & 13.4 & 950 & 5.4 \\
\hline
\end{tabular}

Table 2 Results of the fitting procedure for the peeling measurements. The SI content and peeling velocity $V^{\text {peel }}$ are imposed, $F^{\text {peel }}$ is measured and $L_{\mathrm{d}}$ and $a_{\mathrm{f}}$ are the two fitting parameters (given by the red circles positions as in Fig. 4). The other parameters derive from $L_{\mathrm{dr}}$ and $a_{\mathrm{f}}$, following eqn (1-3) 
where $L_{\mathrm{dr}}$, the length of the debonding region (or cohesive zone) is simply the difference between the two initial fitting parameters.

This novel approach to peeling provides a much richer description than simply measuring a peel force and deriving an adherence energy as is generally done in peeling experiments. The instrumented peeling test thus becomes a sort of local probe providing access to the average stress, the average strain rate and the maximum extensibility of the adhesive in its complex fibrillar debonding region for a given set of control parameters. For each set of conditions, the experiment was repeated 4 times and the error bars represent the total scatter.

The results of the fitting procedure are fully reported in Table 2. The values of the adherence energy, average stress and maximum strain obtained for our four formulations as a function of the peeling velocities are reported in Fig. 6. For each of the formulations, both the adherence energy and the average stress in the debonding region increase when increasing the debonding velocity. However, the effect of adding the diblock is more subtle and does not significantly change the fracture energy as previously reported in probe tack experiments. ${ }^{23}$ This is because while the average stress systematically decreases with the diblock content, the maximum fibril strain at debonding is clearly increasing. Moreover, the instrumented analysis shows that the velocity dependence of the adherence energy is dominated by the stress dependence on the strain rate, while the maximum strain is clearly less sensitive.

\section{Probe-tack test}

The probe-tack test setup was originally designed to test the instant adhesion properties of PSAs, ${ }^{28}$ i.e. for short contact times. In our setup the applied compressive force, time of contact and debonding velocities can be independently controlled. Moreover, experiments can also be performed in a temperature controlled chamber. For the present experiments the temperature was set as ambient conditions $\left(23 \pm 2{ }^{\circ} \mathrm{C}\right)$.

The planarity of the probe/adhesive contact is set by adjusting three-micrometer screws as sketched in Fig. 7. The probe diameter is $1 \mathrm{~cm}$. For all the experiments, the velocity of approach of the probe towards the glass slide is $30 \mu \mathrm{m} \mathrm{s}^{-1}$. The contact formation is done under a compressive force of $70 \mathrm{~N}(0.9 \mathrm{MPa}$ nominal pressure for full contact) and the contact time was $10 \mathrm{~s}$. In the probe-tack test, the debonding velocities $V_{\mathrm{deb}}$ used in this paper are $8 \mu \mathrm{m} \mathrm{s}^{-1}, 80 \mu \mathrm{m} \mathrm{s}^{-1}$, and $800 \mu \mathrm{m} \mathrm{s}^{-1}$. These values were chosen in order to provide nominal strain rates close to those estimated for the debonding region during the peeling tests. The glass probe was cleaned with acetone after each experiment. The measured tack curves of our four formulations and debonding velocities are reported in Fig. 8, after converting the data into engineering stress and strain and correcting for the machine compliance as previously reported. ${ }^{29}$

The main physical parameters extracted from each tack curve are:

1. The plateau stress $\sigma^{\text {tack }}$ (estimated here as the average of the lowest and highest stress in the plateau).
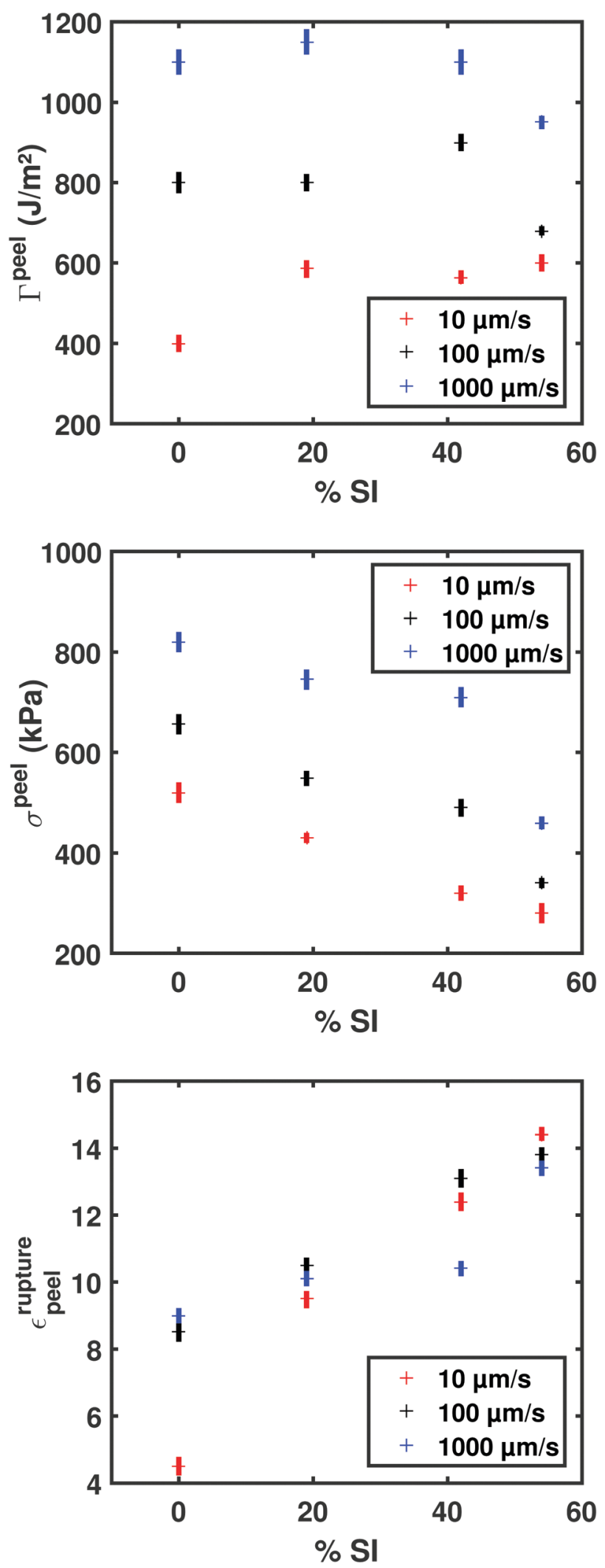

Fig. 6 Adherence energy $\Gamma$, average stress $\sigma$ and maximum fibril strain $\varepsilon^{\text {rupture }}$ in the debonding region during the peeling as a function of the diblock content and peeling velocity. 


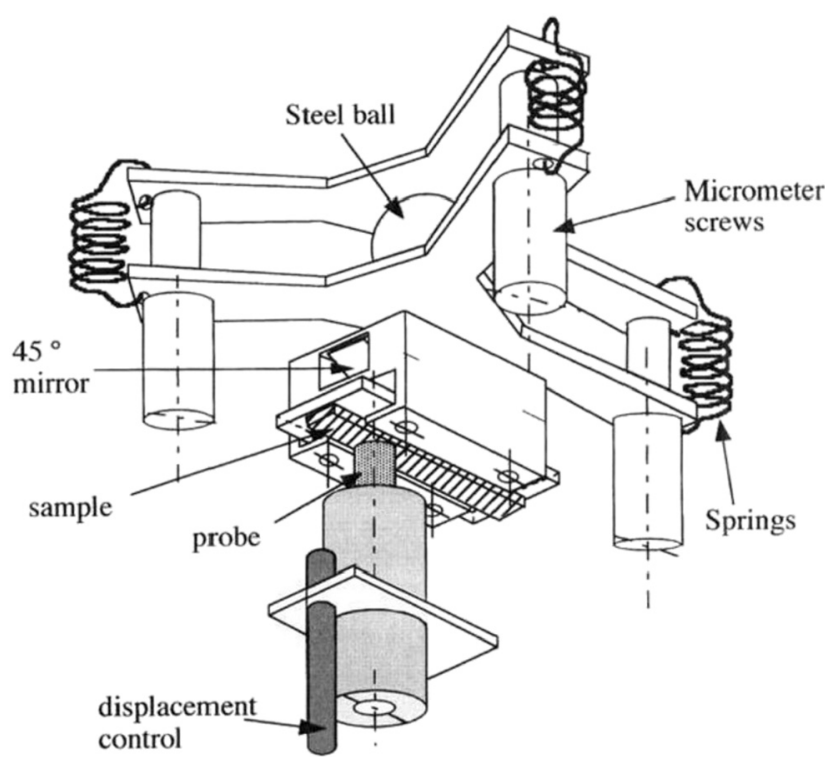

Fig. 7 Probe-tack test setup. The sample is mounted on a reversed glass slide. The flat cylindrical glass probe approaches from below. A side camera through a $45^{\circ}$ mirror images the contact.

2. The maximal strain $\varepsilon_{\text {tack }}^{\text {rupture }}$ (nominal strain at debonding).

3. The nominal strain rate seen by the PSA layer, which is:

$$
\dot{\varepsilon}=\frac{V_{\text {deb }}}{a_{0}}
$$

4. The total adherence energy $\left(\Gamma^{\mathrm{tack}}\right.$ in $\left.\mathrm{J} \mathrm{m}^{-2}\right)$, which is the area under the curve $\sigma(\varepsilon)$ multiplied by the initial thickness $a_{0}$ of the adhesive layer:

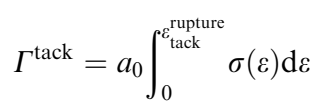

\section{Discussion}

The tack results are consistent with earlier investigations. ${ }^{23}$ The small strain stiffness does not seem to change significantly with the diblock content, because the low strain modulus is mainly related to the entanglement network of the soft phase (isoprene and tackifier), which is not affected by the variation in diblock content. ${ }^{19}$ At larger strains, the plateau stress decreases with increasing diblock content, whereas the strain at rupture increases. This confirms that the large strain behavior is highly controlled by the density of bridges between polystyrene domains, which decreases with increasing diblock content. ${ }^{24}$

Comparing Fig. 6 and 9, very similar features are observed: the dependencies of the observables $\Gamma, \sigma$ and $\varepsilon^{\text {rupture }}$ on the study parameters (strain rate and diblock content) are the same for both test geometries. Using the approach developed in this paper, we indeed have the novel possibility to compare the characteristics of the debonding mechanisms active during steady-state peeling and a probe-tack test under different loading conditions and for different formulations. Hence we report in Fig. 10 the adherence energy, average stress and maximum strain
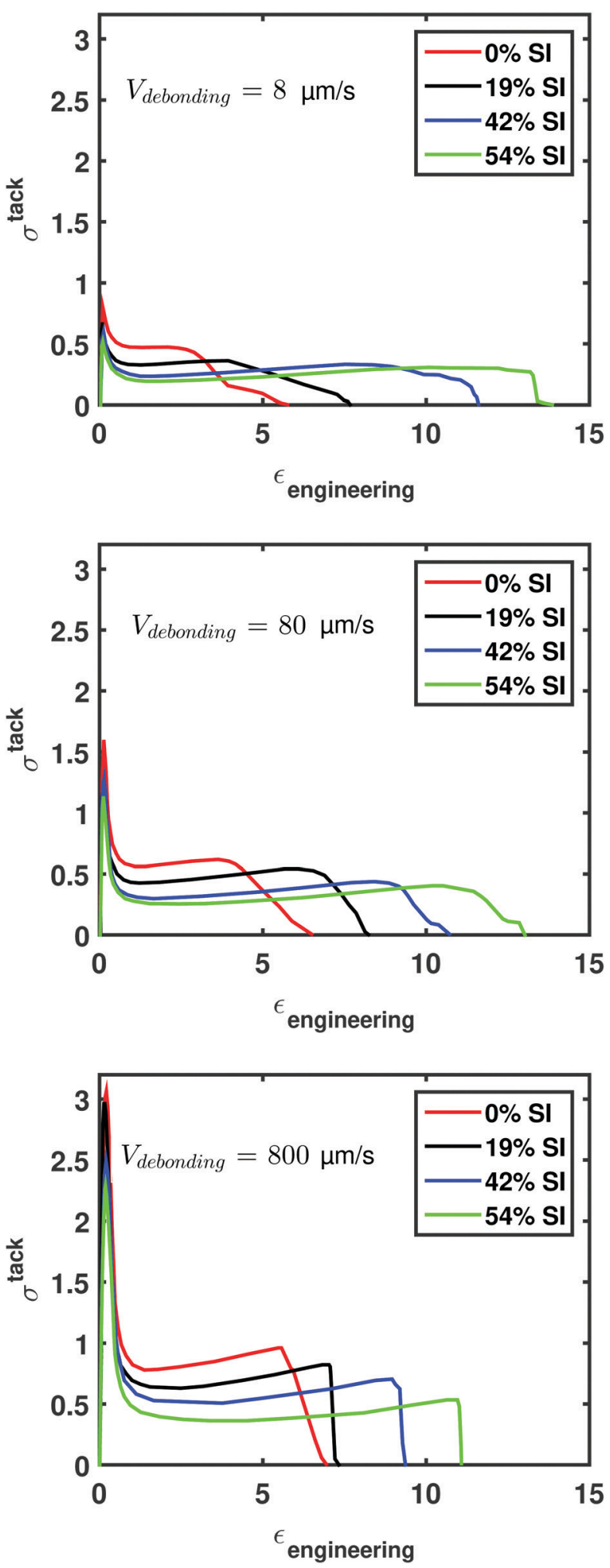

Fig. 8 Tack curves for the four PSA formulations of Table 1 as a function of the $\mathrm{SI}$ content and debonding veclocity $V_{\text {deb. }}$.

at debonding for couples of measurements corresponding to the same average debonding strain rate.

The correlations between these quantities are good, and thanks to the great variation of the properties of this block 

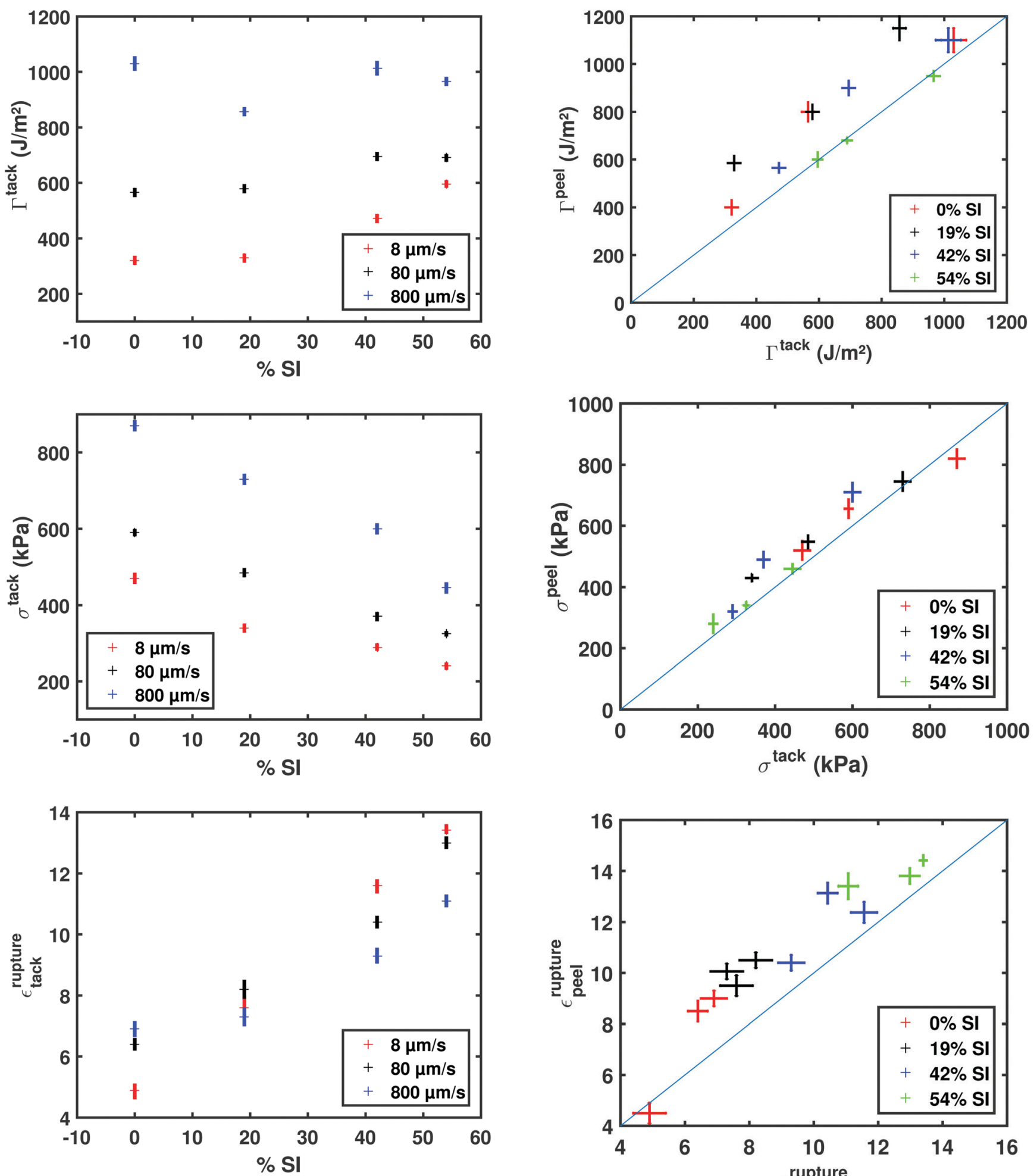

Fig. 9 Fracture energy, average plateau stress and maximum fibril strain derived from the tack curves as a function of the diblock content and peeling velocity. The vertical error bars represent the total scatter in the data.

copolymer system with the diblock content and the average debonding rate, these correlations are also significant. The simultaneous agreement in terms of adherence energy, average stress and maximum debonding strain indicates that when

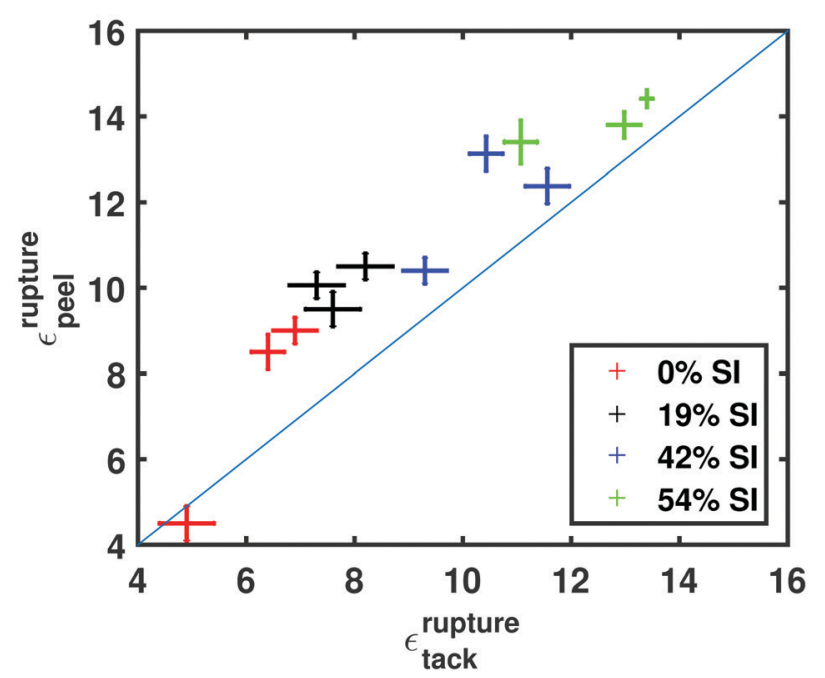

Fig. 10 Comparison of the adhesion energy, average stress and maximum fibril extension during peel and tack tests at the same fibril strain rate. The vertical and horizontal error bars represent the total scatter in the peel data and tack data, respectively.

both the sample thickness (confinement condition) and average debonding strain rates are the same, peel and tack do involve a 


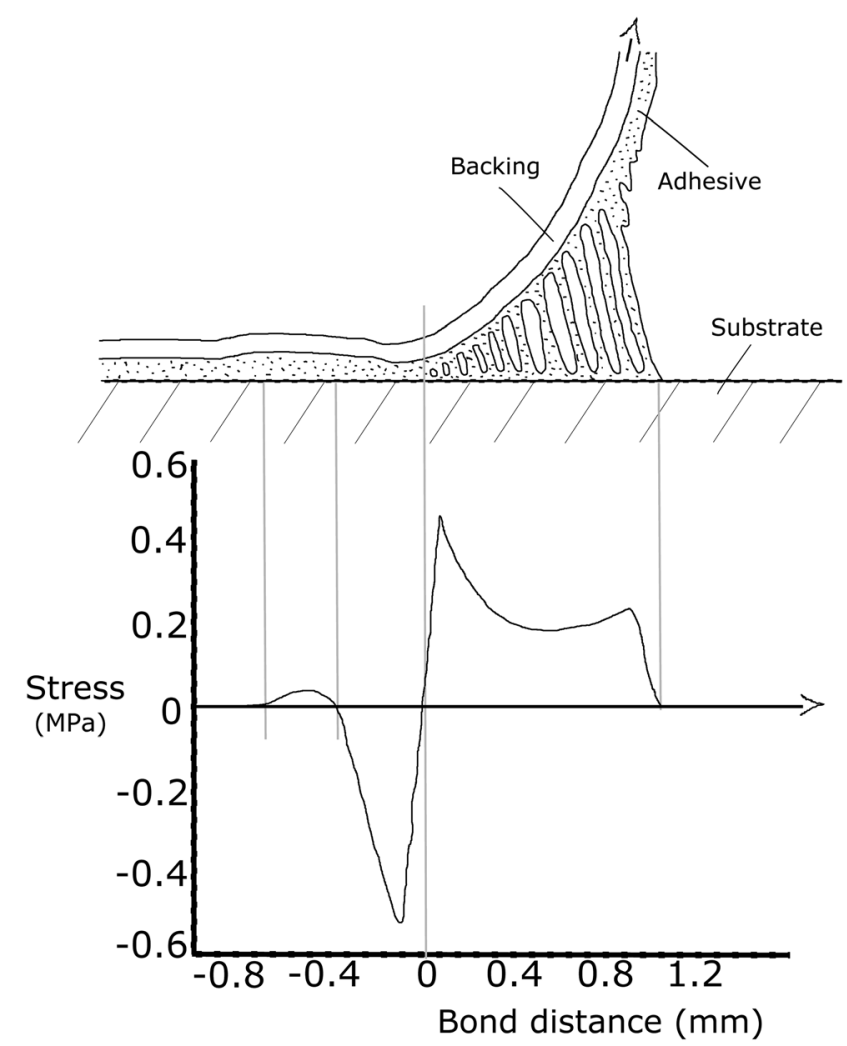

Fig. 11 Stress distribution below the debonding region during peeling as sketched and measured by Kaelble. ${ }^{30}$

very similar local mechanical response of the fibrillated region (provided that the interfacial contact is properly formed). This confirms the intuition based on the observation of the visual aspects of this region in both testing geometries. While the scatter of the data is likely to be caused by the presence of bubbles or non-uniformity of thickness in our custom made samples, we can note the presence of a weak bias making both the average stress and the maximum debonding strain 10\% higher in peel than in tack. This results in a corresponding positive $20 \%$ bias in the adherence energy.

This could partly be associated with the longer contact time ( $\sim 10$ minutes) undergone by the samples before the peel test than in the tack test (10 seconds). On the other hand, part of this difference may also be associated with some intrinsic differences between the two debonding techniques and geometries. The most relevant one is that while peeling describes the steady state propagation of the debonding front, the tack measurement is a transient test probing the global simultaneous debonding of the bonded region. However, when looking in Fig. 11 at the schematic description of the peel front proposed by Kaelble, ${ }^{30}$ we see that while the macroscopic condition of debonding looks very different, each microscopic strand in the debonding region essentially experiences the same local loading history as in tack (see Fig. 8). Moreover, while the overall geometric confinements of the samples were chosen to be similar in the two tests, the local confinement in the debonding region could partially be different due to the smaller lateral dimension of the debonding region for peeling $(<2 \mathrm{~mm})$. We should also remark that the fibrils in peeling are partly tilted before debonding, ${ }^{16}$ while in the tack test the fibrils are mostly vertical.

\section{Conclusion}

The main objective of this study was to transpose the results of probe tests, which give the details of the force displacement curve, to those obtained with the peel geometry, which in its standard form only provides the adherence energy. The model polymer system chosen in our investigation made it possible to change the adhesion performance in a progressive way by varying the diblock content, and in particular to obtain similar levels of adherence energy while changing significantly the large strain rheology. With the recently developed instrumented peeling technique, we could also get detailed information on the dissipative mechanisms in the debonding region during peeling, and estimate important local parameters such as the average stress, the strain at rupture and the fibril strain rate.

These local parameters can be directly compared with the plateau stress and debonding strain typically obtained in a tack test, and thus a direct and more detailed comparison between the deformation pattern of a specific adhesive in peel and tack can be carried out. For similar values of the sample thickness and lateral confinement, we show that when comparing the adherence energy, average stress, and maximum extension as a function of the same fibril strain rate, we obtain very consistent results with both experimental techniques. We could thus prove the deep link between these two debonding tests and identify the fibril strain rate as the main relevant parameter to keep constant when transferring tack properties into the peel properties of a tape.

We should not forget, however, that in standard practice probe-tack tests and peel tests are done under different conditions. The bond formation is generally quite different (in terms of contact time and applied pressure). Moreover, in the tack test the debonding is performed by applying monotonic traction to a fixed region of tape, while in the peel test the debonding is imposed in steady-state conditions and can be more directly related to the propagation of a crack front. If the interfacial bonds are not strong enough, the debonding will occur at smaller strains and fast interfacial crack propagation will prevent fibril formation, thus breaking the strong analogy between peel and tack. ${ }^{1}$ The same can happen if the crosslink density of the adhesive becomes too high, thus providing a stiffer and more elastic character. Nevertheless, our experiments show that when considering typical PSA tapes, which are soft and dissipative, presenting a wide range of adherence energies, the value of the adherence energy is determined in both tests by the strain rate undergone by the fibrils that develop in the debonding region.

These results have important consequences for industrial applications since the evaluation of PSA performances is generally done by combining several different tests such as peeling, tack and shear tests. The development of instrumented peeling can allow the determination of several important properties of 
the debonding mechanisms that are generally only available through the tack test. Moreover, understanding quantitatively the link between peel and tack performances makes it possible to soundly predict peeling performances by only performing tack measurements, which require less material and present better control of the bond formation step. An extension of this investigation to connect these data to the shear performances is currently underway and it would greatly increase the potential of fracture mechanics of soft materials to design and test adhesive tapes under the most general range of loading conditions.

\section{Conflicts of interest}

There are no conflicts to declare.

\section{Acknowledgements}

We thank B. Bresson and L. Olanier for their help in the design of the experiments, and P. P. Cortet, E. Barthel, J. Chopin and D. Yarusso for fruitful discussions.

\section{Notes and references}

1 C. Creton and M. Ciccotti, Rep. Prog. Phys., 2016, 79, 046601.

2 C. Creton, Mater. Res. Soc. Bull., 2003, 28, 434-439.

3 P. S. T. Council, Test methods for pressure sensitive adhesive tapes, PSTC, Oakbrook Terrace, USA, 13th edn, 2000.

4 A. Zosel, Advances in Pressure Sensitive Adhesive Technology, 1992, pp. 92-127.

5 A. Zosel, Colloid Polym. Sci., 1985, 263, 541-553.

6 K. Shull and C. Creton, J. Polym. Sci., Part B: Polym. Phys., 2004, 42, 4023-4043.

7 M. Tirumkudulu, W. Russel and T. Huang, J. Rheol., 2003, 47, 1399-1415.

8 K. Ito, K. Shitajima, N. Karyu, S. Fujii, Y. Nakamura and Y. Urahama, J. Appl. Polym. Sci., 2014, 131, 40336.

9 L. Benyahia, C. Verdier and J. Piau, J. Adhes., 1997, 62, 45-73.

10 E. Chang, J. Adhes., 1991, 34, 189-200.
11 A. Roos, C. Creton, M. Novikov and M. Feldstein, J. Polym. Sci., Part B: Polym. Phys., 2002, 40, 2395-2409.

12 F. Gibert, G. Marin, C. Derail, A. Allal and J. Lechat, J. Adhes., 2003, 79, 825-852.

13 D. Yarusso, J. Adhes., 1999, 70, 299-320.

14 C. A. Dahlquist, Pressure-Sensitive adhesives, in Treatise on Adhesion and Adhesives, ed. R. L. Patrick and M. Dekker, New York, vol. 2, 1969, p. 219.

15 R. Villey, C. Creton, P. Cortet, M. Dalbe, T. Jet, B. Saintyves, S. Santucci, L. Vanel, D. Yarusso and M. Ciccotti, Soft Matter, 2015, 11, 3480-3491.

16 R. Villey, P.-P. Cortet, C. Creton and M. Ciccotti, Int. J. Fract., 2017, 204, 175-190.

17 J. Chopin, R. Villey, D. Yarusso, E. Barthel, C. Creton and M. Ciccotti, Macromolecules, 2018, 51, 8605-8610.

18 D. Satas, Handbook of Pressure Sensitive Adhesive Technology, Springer US, New York, 2nd edn, 1989.

19 A. Roos and C. Creton, Macromolecules, 2005, 38, 7807-7818.

20 C. Creton, G. Hu, F. Deplace, L. Morgret and K. Shull, Macromolecules, 2009, 42, 7605-7615.

21 A. Roos and C. Creton, Macromol. Symp., 2004, 214, 147-156.

22 C. Derail, M. Cazenave, F. Gibert, G. Marin, N. Kappes and J. Lechat, J. Adhes., 2004, 80, 1131-1151.

23 C. Creton, A. Roos and A. Chiche, Effect of the Diblock Content on the Adhesive and Deformation Properties of PSAs Based on Styrenic Block Copolymers, Wiley-VCH Verlag GmbH \& Co. KGaA, 2006, pp. 337-363.

24 K. Daoulas, D. Theodorou, A. Roos and C. Creton, Macromolecules, 2004, 37, 5093-5109.

25 E. Ewins, D. St Clair, J. Erickson and W. Korcz, Thermoplastic Rubbers: A-B-A Block Copolymers, Satas D., Van Nostrand Reinhold, New York, 1989, pp. 317-373.

26 N. Nakajima, R. Babrowicz and E. R. Harrell, J. Appl. Polym. Sci., 1992, 44, 1437-1456.

27 K. Kendall, J. Phys. D: Appl. Phys., 1975, 8, 1449-1452.

28 H. Lakrout, P. Sergot and C. Creton, J. Adhes., 1999, 69, 307-359.

29 G. Josse, P. Sergot, C. Creton and M. Dorget, J. Adhes., 2004, 80, 87-118.

30 D. H. Kaelble, Trans. Soc. Rheol., 1965, 9, 135-163. 